\title{
THE EXPORT BEHAVIOR OF SMALLER-SIZED WISCONSIN MANUFACTURING FIRMS
}

\author{
WARREN J. BILKEY* \\ The University of Wisconsin-Madison \\ GEORGE TESAR* \\ Georgetown University
}

\begin{abstract}
A summary of principal findings regarding the export behavior of $\mathbf{4 2 3}$ small- and medium-sized Wisconsin manufacturing firms. Data were classified according to stages in the export development process and analyzed by multiple regression.
\end{abstract}

Export development is perhaps the most widely studied and least understood aspect of international business - as attested by the large body of literature on international trade and by the extremely empirical approach usually taken by analysts whose unit of study is the firm. ${ }^{1}$ The latter typically use only very simple implicit models for data gathering, and then let the data speak for themselves. This approach has yielded an array of noncomparable information. A commonly acceptable export model is needed.

The analysis summarized here explores the meaningfulness of a "stages" model for examining export behavior, particularly of small- and medium-sized firms. Such a model could be integrated into broader "stages" concepts of the firm. It also leads to policy implications that differ from that of non-stage concepts.

The model used is - that the export development process of firms tends to occur in the following stages:

- Stage One. Management is not interested in exporting; would not even fill an unsolicited export order.

- Stage Two. Management would fill an unsolicited export order, but makes no effort to explore the feasibility of exporting

- Stage Three (which can be skipped if unsolicited export orders are received). Management actively explores the feasibility of exporting

-Stage Four. The firm exports on an experimental basis to some psychologically close country.

-Stage Five. The firm is an experienced exporter to that country and adjusts exports optimally to changing exchange rates, tariffs, etc.

-Stage Six. Management explores the feasibility of exporting to additional countries that psychologically, are further away.

-And so on

Additional propositions in this model are: that the determinants of firms' behavior are ascertainable empirically, and that they may differ from one export stage to another.

To test the above model, questionnaires were mailed to a sample of 816 Wisconsin firms in April 1974. They were drawn randomly from the 4,701 listings in the Classified Directory of Wisconsin Manufacturers, 1974 (published by the Wisconsin Manufacturers' Association) that met criteria

* Warren Bilkey is Professor of Business at the University of Wisconsin-Madison. He received his doctorate in economics from Harvard University. He served for a period as economics adviser to the President of the Dominican Republic and has published in the fields of international business, economic development, and consumer behavior.

George Tesar is an Assistant Professor of Marketing and International Management at Georgetown University and an Associate at the Center for Strategic and International Studies in Washington, D.C. He received his MBA from Michigan State University and Ph.D. from the University of Wisconsin. His research, professional, and publication interests include internationalization of firms and organizations and East-West trade. 
which: tended to limit questionnaire mailings to small- and medium-sized firms, enabled the questionnaire to reach the top management of each firm, and provided a basis for estimating the SIC distribution of the respondents. Altogether, 423 fully completed responses were received $(52 \%$ of the sample). A comparison of the size distribution of responding firms with the universe from which the sample was drawn indicated that the responding firms were reasonably representative of the population.

The analytical methodology involved treating each stage of the export development process as the dependent variable of a multiple regression equation. The same dependent variables were tested for each stage by means of step-wise multiple regression analysis, adding variables so long as they improved the (unbiased) coefficient of multiple correlation. Only the general findings are presented below; correlations and equations are given in footnotes, and the questions to which they relate are in the appendix to this article. Detailed findings may be obtained by writing to either of the coauthors.

SUM- A multiple regression analysis was made first of Stage Three (exploring the feasibility of exporting).

MARY OF

THE

FINDINGS
The dependent variable was whether management had explored the feasibility of exporting. A dummy value of one was imputed if they had; a value of zero was imputed if they had not. No meaningful correlations were found with managements' profit nor other expectations regarding the effect of exporting on their firm. ${ }^{3}$ The highest partial correlation $(+.447)$ was with whether or not management planned for exporting; the next highest partial correlation $(+.154)$ was with managements' perceptions of their firms' competitive advantages. This finding raised an interesting causality question. If planning for exporting was the most important determinant of exploring the feasibility of exporting, and managements' specific expectations regarding exporting bore no relation with whether or not those firms had explored the feasibility of exporting, what induced some of them to plan for exporting? A study by Simpson suggests that part of the answer may be managements' diffuse impression of whether exporting is desirable per se, independently of whatever contribution it might make to their firm. ${ }^{4} \mathrm{~A}$ study by Langston and Teas suggests that another part of the answer may be managements' image of foreign areas. ${ }^{5}$ They found that exporting by smaller-sized U.S. manufacturing firms correlates with: whether or not an official of the firm had studied a foreign language while in school; whether that official had lived abroad sufficiently long to have experienced cultural shock; and whether that experience abroad was attractive-e.g., having been a soldier in Viet Nam would militate against a firm exporting. In other words, Stage Three of the export development process seems to be much more nearly a function of managements' general images of exporting and of foreign lands than of immediate economic considerations!

The overwhelmingly most important single determinant of whether or not those firms entered Export Stage Four-exported experimentally-was the receipt or non-receipt of an unsolicited initial export order. ${ }^{3}$ (Approximately $60 \%$ of the exporting firms in this study received their initial export order unsolicited.) The next most important determinant was the quality and dynamism of the firms' management. Why were profit and growth expectations so relatively unimportant? A logical answer is that the purpose of experimental exporting is to discover precisely what exporting can contribute to the firm. Prior to such experience, management's expectations are based only on estimates which are inherently imprecise; management cannot have much confidence in them.

For the firms in Export Stage Five (experienced exporters) rational decision making, consistent with the Marshallian theory of the firm, was found..$^{7}$ Expectations and perceived barriers were the overwhelmingly important independent variables. The negative partial correlation coefficient for management shown in footnote seven is puzzling until one realizes that the most dynamic managements probably had already established production facilities abroad-which cause their exports to be lower than the exports of firms without such facilities.

The multiple regression format used in our analysis indicates that a low value for one independent variable can be compensated by high values for one or more of the other independent variables. If this were untrue, the multiple regression format would be subject to suspicion. Accordingly, the firms in Export Stage Four (experimental exporters) were dichotomized according to whether or not their initial export order was unsolicited. Analysis showed that compared with the firms whose initial export order was unsolicited, the firms that obtain their own initial export order:

-were much larger (almost two-and-a-half times as many employees);

-had much favorable expectations regarding the advantages of exporting for their firm; 
These differences are in harmony with a multiple regression formulation for the relationships involved.

Perceived barriers to exporting were found to be meaningful only for firms in Export Stage Five (experienced exporters). It was noted, however, that the composition of certain of the perceived barriers tended to differ systematically by export stage. The following varied directly with export stage; that is, the further advanced the export stage, the greater the per cent of the firms that perceived these considerations as a barrier to exporting:

-Difficulty in understanding foreign business practices.

-Different product standards and consumer standards in foreign countries which make U.S. products unsuitable for export.

-Difficulty in collecting money from foreign markets.

_Difficulty in obtaining adequate representation in foreign markets.

In addition, one perceived barrier was found to differ inversely with export stage: difficulty in obtaining funds necessary to get started in exporting.

The data from this study are consistent with the following propositions:

-The export development process of firms tends to proceed in stages. (The findings are in harmony with the particular stage sequence listed at the beginning of this note, but not all of them were tested.)

- Consideratons that influence firms' progressions from one stage to the next tend to differ by stage for the three stages examined.

-Within the size-range of firms studied, size was relatively unimportant for export behavior when account was taken of the quality and dynamism of management.

The above propositions should be thought of as tentative conclusions subject to further tests. To the extent that they are verified, they have the following implications:

1. Learning theory is applicable to the export development process. This suggests that business consulting programs, such as the SOAR projects promoted by the U.S. Department of Commerce among business schools, must be appropriately focused to each firm's export stage if they are to be relevant. ${ }^{8}$ This also suggests that the export management needs of firms at one export stage may be very different from the needs of firms at another stage. In addition, learning theory suggests that firms at early export stages should focus on psychologically close countries (in harmony with Linder's theory of exporting), and firms at later stages should focus on psychologically more distant countries.

2. Government programs for increasing manufactured exports should consider two foci that can be conceptualized in terms of an aggregative export supply curve (where the horizontal axis is the real value of the country's total exports, and the vertical axis is real export profitability for that country's firms). One focus is to move upward along the export supply curve by making exporting more profitable-this is relevant for firms in Export Stage Five (experienced exporters). The second focus is to shift the export supply curve to the right-by increasing managements' international interests (perhaps promoting foreign language instruction, foreign visits, international business education, etc.), by obtaining export orders for firms, by instituting management development programs, by removing perceived barriers to exporting, and so on. This is relevant for firms at all export stages, but especially for firms in Stages Two through Four and Stage Six and beyond.

3. Closely related to the above inference is that a government seeking to stimulate manufactured exports probably would find it desirable to undertake a complex of programs, so that something would be appropriate for firms at each stage of the export development process. Alternatively, should the government choose to concentrate on some one export development program, it probably should choose the one with the highest benefit/cost payoff. In the latter case, a country with a large per cent of its firms in Export Stage Five (e.g., an industrialized country) seemingly should use a different program than a country having a large per cent of its firms in Export Stage One (e.g., a developing country). In other words, a developing country should not blindly imitate the export development programs that are appropriate for an industrialized country.

4. To the extent that the conclusions from this study are confirmed by other studies and the specific findings obtained can be generalized, managements interested in exporting should:

-follow through on whatever unsolicited export orders arrive, for they can be a means of shortening the firm's export development process.

-formulate an export policy.

\section{CONCLUSIONS AND IMPLICATIONS}


-formulate an export plan

-make some person or department specifically responsible for the firm's export development.

-direct the firm's initial export efforts to psychologically nearby countries; then, as experience is gained, extend exporting to psychologically more distant areas.

- search for information regarding relevant export barriers, to be aware of what must be overcome during the firm's export development process.

- develop exporting on a step-by-step basis to progress rationally from one export stage to the next. Export Stage Three (exploring the feasibility of exporting) can be skipped if unsolicited export orders are received. No evidence suggested that other export stages could be eliminated.

5. This study indicated that small- and medium-sized firms can export successfully; exporting is not limited to large firms.

1. W. J. Bilkey, "An Attempted Integration of the Literature on the Export Behavior of Firms" (Paper presented at the Middle East meeting of the Academy of International Business in Alexandria, Egypt, December 30, 1976).

2. Sune Carlson, "How Foreign is Foreign Trade?", Acta Universitatis Upsaliensis, Studia Oeconomiae Negotiorum, No. 11 (Uppsala, Sweden, 1975). A psychologically close country has the same culture, is at a similar stage of economic development, etc, as the country in question. Thus, Australia is psychologically closer to most U.S. firms than is Haiti, even though the latter is nearer geographically.

3. The regression equation for Export Stage Three (exploring the feasibility of exporting) is

$X=.020+.465 L+.032 C$

where

$X=$ Whether or not management actively explored the feasibility of exporting ( $1=y e s, 0=$ no).

$L=$ Whether or not management planned for exporting ( $1=y e s, 0=n o)$.

$C=$ Management's perception of its firm's competitive advantages (score $=-2$ to +4 ). the (unbiased) $R^{2}$ for this equation was only 241 .

4. C. L. Simpson, Jr., "The Export Decision: An Interview Study of the Decision Process in Tennessee Manufacturing Firms" (Ph.D. dissertation, Georgia State University, Atlanta, Georgia, 1973).

5. C. M. Langston and R. K. Teas, "Export Commitment and Characteristics of Management" (Paper presented at the annual meeting of the Midwest Business Association, St. Louis, Missouri, April 2, 1976).

6. Export Stage Four (experimental exporting) was analyzed by sorting the responding firms into two groups: those who were experimental exporters (had been exporting for two years or less and whose value of exports was less than $10 \%$ of the value of their total sales); and those who had not yet started to export. This difference was treated as the dependent variable. Step-wise multiple regression yielded (unbiased) $R^{2}=.690$ for the independent variables used. Their partial correlations with the dependent variable were:

-Whether or not the firm's initial export order was unsolicited $(U)=+.735$.

-A composite of five variables measuring the quality and dynamism of the firm's management $(M)=+.396$.

-Management's expectations as to what exporting would contribute to its firm's goals $(E)=+.241$.

-Firm size, measured by the number of employees $(S)=+.183$.

The regression equation for Export Stage Four (experimental exporting) is

$\mathrm{A}=-.1393+.0002 \mathrm{E}+.105 \mathrm{M}+.692 \mathrm{U}+.046 \mathrm{~S}$

where

$A=$ Whether the firm exports experimentally $(1=$ yes, $0=$ no)

$E=$ Management's expectations as to what exporting would contribute to its firm (scaled range $=-1,000$ to $+1,000$ )

$M=$ Management, scaled as a composite of the following five current considerations, all weighted equally:

$W=$ Managerial views.

$D=$ Whether the firm has a special structure, such as a department, for evaluating exports ( $1=y e s$, $0=$ no).

$P=$ Whether management has a more-or-less fixed policy regarding exporting ( $1=y e s, 0=n o)$

$\mathrm{L}=$ Whether management plans for exporting $(1=y e s, 0=\mathrm{no})$.

$X=$ Whether management has systematically explored the feasibility of exporting $(1=y e s, 0=$ no $)$.

$U=$ Whether the firm's first export order was unsolicited ( $1=y e s, 0=$ no).

$S=$ The firm's size as measured by the number of employees (categorized as follows: $1=<25 ; 2=25-99$; $3=100-249 ; 4=250-499 ; 5=500-1,000 ; 6=>1,000$ ).

7. Firms in Export Stage Five (experienced exporters) were defined as those exporting for six years or longer, and whose exports were $10 \%$ or more of total sales on a value basis. The dependent variable was the per cent of sales exported by those experienced firms. Step-wise multiple regression with the variables used yielded (unbiased) $R^{2}=698$. Their partial correlations with the dependent variable were:

- Management's expectations as to what exporting would contribute to their firm's goals $(E)=+.775$.

-The number of barriers to exporting perceived by management, each of which makes exporting extremely

difficult or impossible, e.g., foreign import quotas, lack of foreign market information, etc. $(B)=-.531$. 
The regression equation for Export Stage Five (experienced exporters) is:

$\mathrm{D}=.3151+.0004 \mathrm{E}-.048 \mathrm{~B}-.041 \mathrm{M}$.

where:

$D=$ Per cent of the firm's total sales, in value terms, currently being exported (range $=.10$ to .45 ).

$E=$ Management's expectations as to what exporting would contribute to their firm (scaled range = $-1,000$ to $+1,000$ )

$B=$ The number of barriers management perceives to exporting (range $=0$ to 9 )

$M=$ Management, scaled as a composite of the same five variables listed in Footnote Six (range $=-.05$ to $+4.5)$

8. This problem was reported in W.J. Bilkey, "A University Experience With the MBA Export Expansion Program," Journal of International Business Studies, Vol. 4, No. 1 (Spring 1973), pp. 15-29. At that time, the reason for the problem was unclear.

The data for this study were obtained by a mailed questionnaire which measured variables in the regression equations as follows.

1. The dependent variable $(X)$ for the equation in Footnote Three was measured dichotomously by the following question: "Has your firm ever systematically explored the possibility of exporting any of your products? ( ) Yes, ( ) No." The dependent variable (A) in Footnote Six was measured dichotomously by the question: "Does your firm presently export any of its products? ( ) Yes, ( ) No." The dependent variable (D) in Footnote Seven was measured continuously by the question: "Approximately what percentage of your firm's sales is derived from exports? () under 10\%, ( ) 10\% - 19\%, ( ) $20 \%-29 \%$, ( ) $30 \%-39 \%$, ( ) $40 \%$ or over.

2. Management's expectations $(E)$ regarding the effects of exporting were treated as a two-stage variable composed of attitudes and values. Attitudes were measured by the question shown in the upper part of Chart 1 , which provided a five-point scale as follows

\section{Chart 1}

Questions Used for Measuring Management's Expectations (E) Regarding the Effects of Exporting

\section{Attitudes}

What is, or would be during the immediately foreseeable future, the effect of exporting on each of the following considerations? [Check one for each of the following considerations.]

\author{
a. Your firm's profits. \\ b. Your firm's growth. \\ c. Security of your firm's investment. \\ d. Development and/or security of your \\ markets. \\ e. Contribution to the development of \\ the U.S. economy.
}

\begin{tabular}{|c|c|c|c|c|}
\hline-2 & -1 & 0 & +1 & +2 \\
\hline 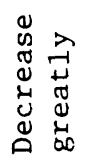 & 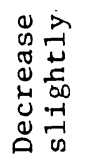 & 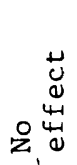 & 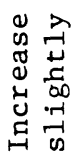 & 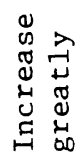 \\
\hline () & () & $\begin{array}{l}(\text { ) } \\
(\text { ) }\end{array}$ & $\begin{array}{l}(\text { ) } \\
(\text { ) }\end{array}$ & () \\
\hline() & () & ( ) & ( ) & ( ) \\
\hline() & ( ) & ( ) & ( ) & \\
\hline ) & $($ ) & () & ( & \\
\hline
\end{tabular}

Values (Weights)

For each of the following types of goals, indicate in the blank provided the thermometer-scale number that expresses its current importance to your firm.

\footnotetext{
a. High profit rate on investment

b. High growth rate

c. Security of investment

d. Development and/or security of your markets

e. Contribution to the development of the U.S. economy
}

\section{APPENDIX}


The response "decrease greatly" was coded as -2; "decrease slightly" was coded as -1; "no effect" was coded as 0 ; "increase slightly" was coded as +1 ; and "increase greatly" was coded as +2 . The weight imputed to each consideration (profit, growth, etc.) was scaled by the lower part of Chart 1 . The two sets of scores then were tied together multiplicatively to yield weighted attitudes. To illustrate, suppose that a respondent evaluated profit as 80 , and indicated an attitude that exporting would "increase his firm's profits greatly," which was coded as +2 . Then the two answers would be multiplied to yield a product $(+2 \times 80=+160)$. This was done for each of the five goals listed. The sum of all five products for each respondent was tabulated as his expectations $(E)$ regarding the effects that exporting during the immediately foreseeable future would have on his firm. This is an application of multiple criteria decision making.

3. Management (M) was measured as a composite of five elements. One was an index of Filley-House managerial views, calculated as follows. A list of managerial statements was compiled which a panel of eleven persons, all familiar with the Filley-House model, then classified into each of the three growth levels (a, craftsman level; $\boldsymbol{\beta}$, promoter level; and $\boldsymbol{\gamma}$, rational organization level). Statements from this list were retained only if all panel members agreed that they reflected a given level of the Filley-House model. Managers receiving the questionnaire then rated each statement on a five-point scale where: $1=$ strongly disagree, $2=$ slightly disagree, $3=$ undecided, $4=$ slightly agree, and $5=$ strongly agree. Our index of Filley-House managerial views (W) was the sum of scores for the level $y$ statements minus the sum of scores for the level a statements.

The second component of Management (M) was structural: whether the firm had a formal structure for evaluating export opportunities. This was coded as a dummy variable, where $1=$ yes and $0=$ no.

The third and fourth components of Management $(\mathrm{M})$ were carrying out the following basic managerial activities regarding exporting, each coded as a dummy variable, where $1=$ yes and $0=$ no.

-Whether the firm has a more or less fixed policy regarding exporting $(P)$.

-Whether the firm plans for exporting $(L)$

The fifth component of Management (M) was managerial initiative regarding exporting. It was measured as a dummy variable ( 1 = yes, $0=$ no) from the question, "Has your firm ever systematically explored the possibility of exporting any of your products?" Scores for these five components were standardized so that each had equal weight; $(M)$ was scaled as the unweighted sum of those five scores.

4. External intervention was measured as a dummy variable ( $1=y e s, 0=$ no) according to whether the firm's first export order was unsolicited $(U)$. The rationale is that institutions outside the firm such as "Japanese-type" trading companies, government advertising programs, trade fairs, etc., will, if successful, create export opportunities.

5. Perceived barriers (B) were measured by the number of items checked in response to the following question, "Check which, if any, of the following barriers to exporting are so serious as to make it extremely difficult or impossible to export: ( ) foreign opportunities are difficult to determine; ( ) it costs too much money to get started in exporting; ( ) adequate representation in foreign markets is difficult to obtain; ( ) it is difficult to collect your money overseas; ( ) different product standards and consumer habits make U.S. products unsuitable for exports; ( ) service is difficult if not impossible in foreign markets; ( ) foreign business practices are difficult to understand; ( ) shipping documents, export licenses, and other paperwork require too much time; ( ) it is difficult to convert some currencies into U.S. dollars." This list of barriers was derived from preliminary interviews with twenty-three firms. The total of all barriers checked is referred to as B.

6. Size (S) was measured by the number of employees in the firm.

7. Management's perceived competitive advantages $(C)$ were scaled from the following question which reflects their perceived position on the international product life-cycle. "Which of the following advantages have helped your firm compete more successfully? ( ) technology, ( ) efficient production methods, ( ) unique product, ( ) efficient marketing techniques, ( ) proximity to market." A score of plus one was given to each of the first four advantages checked; these items represent an early stage of the international product life-cycle. A score of minus two was given if the last item was checked, for that item represents a late stage of the international product life-cycle. 